\title{
Experiences of nurses working in a rural primary health-care setting in Mopani district, Limpopo Province
}

\author{
MP Mohale, MCur \\ University of Pretoria
}

FM Mulaudzi, D Litt et Phil, RN

North West University (Potchefstroom Campus)

Key words:

primary health care, experience, rural

\section{Correspondence address: \\ FM Mulaudzi \\ North West University \\ (Potchefstroom Campus)}

Tel : (018) 299-2396

Fax : (018) 299-2399

Email:mavis.mulaudzi@nwu.ac.za

\section{Abstract: Curationis 31(2): 60-66}

Professional nurses working in rural primary health-care settings are experiencing burnout due to serious shortages of personnel. This is exacerbated by the brain drain of nurses leaving the country. Rural settings are resource constrained in terms of personnel and equipment. This results in dissatisfaction among nurses due to the unbearable working conditions which result in stress and frustration. A qualitative, explorative, descriptive study was conducted to explore and describe the experiences of nurses working in a rural primary health-care setting in the greater Letaba subdistrict in Limpopo Province. Purposive sampling was used to identify the participants. Data was collected in the form of in-depth interviews. The study revealed that nurses working in primary health-care settings were experiencing emotional and physical strain as a result of the shortage of human resources. It was recommended that policies that meet the health-care needs of rural communities be developed, and that strategies to retain professional nurses in primary health-care settings be formulated.

\section{Introduction and background of the study}

The goal of the Healthy People 2010 Initiative is to reduce or eliminate health disparities in vulnerable populations, including populations with rural and minority ethnic backgrounds (Averill, 2002:624). Despite the progress made by African countries in the last decade in terms of developing national systems based on primary health-care principles, the issue of balancing the demand and supply of the health-care workforce in rural areas is still a problem. In developing sub-Saharan African countries, health issues have proved to be the most complicated and difficult policy issues to resolve (Akisola \& Ncube, 2000:49-50). As a result of a lack of social amenities, attracting and retaining medical doctors and nurses has long been a problem.

The demands on the nurses in rural areas are multiple and diverse (Busby \& Busby, 2001:306). Often, in rural primary healthcare settings, one registered nurse is placed on duty with only a nursing assistant and no attending physician at the clinic, either during the day or at night. The primary health-care facility is managed on a daily basis by a single qualified professional nurse. This contributes to excessively high workloads and the poor performance of these nurses, which can tarnish the reputation of nurses in the eyes of the communities. There are some nurses who find job satisfaction in the greater autonomy they are afforded in these areas. They enjoy serving the communities and convert the problems 
they experience into challenges and opportunities. In settings where professional nurses work cohesively with other health professionals, according to Hegney, McCarthy, Clark and Gorman (2002:130) and Fuszard, Green, Kujala and Talley (1994b:38-9), it has been demonstrated that clients feel a strong ownership of their health.

In 1994, the new government of South Africa committed itself to the integration and sustainability of its programme through a restructuring and development programme (RDP). One of the objectives set at this time was that primary health care be made available to pregnant women and children younger than six years old at no cost. The aim was to later expand this service to all citizens. Ironically, there was no programme initiated to increase staff or material resources to maintain and run these health services.

Low staff ratios, high workloads and a growing population led to an increase in the utilisation of personnel with fewer skills and a decline in the quality of care offered. The working conditions caused many nurses to decide to leave the profession or to emigrate from South Africa. The supermarket approach or the integration of services approach contributed to the stress and burnout of rural nurses working in primary health care. The lack of both material and human resources resulted in poor performance in nursing in rural primary health-care settings.

In the Greater Letaba sub-district the workload problem still exists, with newlyqualified nurses being appointed to primary health-care facilities which should be run by experienced professional nurses. These nurses work independently, fulfilling all day-to-day supervisory and managerial duties, while they are not yet skilled or knowledgeable in this sphere of service. Primary healthcare nurses working in rural communities are faced with problems as they are working in areas suffering from gross shortages. In greater Letaba sub-district, nurses render a 24-hour service to the community and are therefore often on call for 24 hours a day, seven days a week, taking breaks at lunch and suppertime. The integration of services approach is practised in this area. The purpose of the study on which this article is based was to explore and describe the experiences of nurses working in rural primary healthcare settings. This article presents the findings of the study, and their potential implications for policy implementation. It recommends how to strengthen policy implementation and service delivery in South Africa.

\section{Research design and methods}

A qualitative, descriptive and exploratory research design was used to answer the research question. The population of this study comprised professional nurses working in clinics that render either eighthour or 24-hour services in greater Letaba sub-district in the Mopani district in Limpopo Province. The participants were selected purposively from four clinics. Purposive sampling was used to identify the participants. The sample of participants included nurses both trained and untrained in primary health care who had worked in the primary health-care setting for more than six months. In this study data were collected by means of unstructured interviews which lasted 45 to 60 minutes each, using the direct contact approach. According to Brink (1996:158), unstructured interviews are conducted more like normal conversation, but with a purpose.

During the interviews probing questions were asked in order to elicit more information from the participants and show participants that the researcher was interested in their experiences. The researcher collected the data personally in order to ensure that it was done in a systematic manner. The interviews were recorded by means of a tape recorder to prevent loss of data, and transcripts were made of the recordings. The researcher made appointments with the participants and interviewed them while they were off duty at the clinics where they worked, or at their homes. The researcher ensured that the interviews remained consistent by asking one broad central research question:

What are the experiences of nurses working in rural primary health-care settings?

Data were collected until saturation was reached. Saturation was reached by the $9^{\text {th }}$ participant. The researcher continued with another three interviews, hoping that new information may come up. In the end the sample was comprised of eleven female professional nurses who had worked in the clinic for more than six months. The interviews were held in Northern Sotho as the participants felt more comfortable communicating in their mother tongue. The researcher then translated the interviews into English.

\section{Trustworthiness}

According to Lincoln and Guba (1985:290-9), and Lincoln and Guba (1985, in Klopper, 1998:314-6), there are four aspects to trustworthiness, namely credibility, transferability, dependability and conformability.

\section{Credibility}

According to Polit and Beck (2004:36), credibility is an aspect of research that is achieved when confidence in the truth of the data and interpretation is attained. De Vos (1998:312) notes that credibility is established if it is demonstrated that the research was conducted in a manner that ensures that the phenomena were accurately identified and described. In this study the researcher ensured the credibility of the research through immersion in the field, making use of a variety of sources of data, and building trust and rapport with the participants.

\section{Transferability}

Applicability is an important factor in transferability, and allows the researcher to present and describe data in such a manner that another person can compare them to the findings of other studies (Lincoln \& Guba, 1985, in Klopper, 1998:316). Thick descriptions of the methodology were used to describe the experiences of the primary health-care nurses in rural settings to enable the reader to understand the phenomenon to the extent that he/she would be able to transfer the results to other settings

\section{Dependability}

Dependability is determined by the extent to which the findings of the study would be consistent if the enquiry were replicated with the same subjects in a similar context (Lincolin \& Guba, 1985 in Klopper, 1998:316). Prolonged engagement with participants increased the dependability of the research.

\section{Confirmability}

To achieve confirmability, it is important that the researcher remains neutral. The researcher should not be biased and his/ her perspectives and motivations should 
not impact on the study. In this study the researcher obtained valued information through prolonged contact with the participants, observing them during data collection and decreasing the distance between the researcher and the participants' conversation, without allowing bias or own perspectives to influence the conversations. An audit trail was done by giving the tapes to an independent coder who also listened to the interviews. A meeting was held with the independent coder to compare and verify the findings. The supervisors of the study also listened to the tapes to verify the conclusions, interpretations and recommendations.

\section{Ethical considerations}

Permission to conduct the study was granted by the Limpopo Province Department of Health Research Committee. Once the letter of permission was received, copies were sent to the manager of primary health care in Greater Letaba sub-district, as well as the participants. The researcher informed the participants regarding the purpose, methods and procedure of the study. The participants made an informed choice to take part in the study, and did so freely and voluntarily. They were asked to sign a form to indicate that they had given their informed consent to be interviewed, and were informed that they could refuse to answer any question or discontinue their participation at any time (Averill, 2002:656). The privacy of the participants was respected throughout the study and all information collected during the study was kept strictly confidential (Polit \& Hungler, 1991:35). The participants' anonymity was ensured by substituting their names with numbers or codes. Participants were treated fairly and any unclear information was clarified for them during the study (Polit \& Hungler, 1991:35).

\section{Discussion of findings}

According to Polit and Hungler (1991:460), data analysis is a systematic organisation of data synthesis and testing of the research hypothesis using those data. In the study qualitative analysis of data was done. Similar topics were clustered together, categorised and sub-categorised, and common themes identified. The Tesch method of data analysis was used (De Vos, 2002:318). Data from the interview transcripts were grouped into five categories: emotions, constraints in caring, infrastructural constraints, relationship constraints and personal issues.

\section{Category 1: Emotions}

The following themes emerged from the category: emotions:

Participants expressed emotions such as anger, sadness, fear and suffering. They also indicated that in certain instances they felt frustrated and hopeless. They said that working 24-hour shifts from 07:00 to 19:00 and being on call from 19:00 to $07: 00$ was strenuous, especially because patients did not understand that when they were on call they dealt with emergencies only. Patients did not want to stand in long queues during the day. They stayed at home and pitched up during the night for minor ailments.

Participants experienced emotions such as anger at management for introducing policies such as "Batho pele" (people first) and the patients' rights charter. They said that they understood and appreciated that those policies where formulated to protect patients' rights. However, they felt left out as patients often quoted those policies to force them to work long hours and attend to minor complaints after hours.

The following was said:

"I know that 'Batho pele' principles and Patients' Rights Charter were formulated to bring harmony between the client and us but sometimes I feel like they were formulated for the community to oppress us for even if they come during the night to fetch condoms. One cannot send them away because of the Batho pele principles."

The Batho pele principle emphasises that clients must have access to services and that clients must be treated with courtesy (White Paper on Transforming Public Service Delivery). The participants verbalised that those two principles stated that every client/patient must be assisted and not turned away. Participants reported that they were the ones who experienced the strenuous part of the job while policy-makers who formulated "Batho pele" were in their offices dictating to them what to do and what not to do, thus they experienced it as an unfair practice on their part.

Busby and Rauh (1991:19) state that nurses working in rural areas need to have a good relationship with community members as rural residents are acquainted with one another. In this situation, information is quickly disseminated among community members, especially when the local news concerns matters of life, illness and death. Turning away a patient at night may cause a stir and dissatisfaction among clients and consequently among members of the community. In turn, when patients with minor ailments come to the facility for consultation at night they find nurses exhausted by the day's routine. According to Wiens (1990:16), lack of time due to inadequate staffing precludes quality patient care. Chalmers, Bramadat and Andusyszyn (1993: 113) mention that lack of rural human resources can impose an additional burden on nurses, thus contributing to anger, sadness, suffering and frustration, which lead to high staff turnover

\section{Category 2: Infrastructural constraints}

The participants expressed that they experienced infrastructural constraints, including lack of basic necessities such as accommodation, communication systems, water and electricity. The participants felt frustrated about the shortage of water. Safe water is a basic need and should be made available to all. Managers should respond promptly to requests made by professional nurses at rural primary health-care facilities, as they serve the community in isolated areas and are thus the eyes and ears of their managers.

As I am talking right now we have not had water for the past three weeks; patients assist by bringing water with small tubs. Families are expected to bring water along when they bring $a$ woman in labour. The problem has not been attended to despite repeated requests. The toilets are a big health hazard when we are without water. In this situation how are we expected to teach the community about a safe water supply and and usage?

Van der Merwe (1999:1273) states that people in rural areas have limited access to electricity and water. Dennill et al. (1995:5) conclude that primary health care includes a supply of safe water and sanitation. Water shortages increase the likelihood of the community's contracting infectious diseases such as cholera, typhoid and diarrhoea.

In support of lack of electricity, participants expressed the following 
problems:

"We have to walk by torchlight at night from the nurses' home to the clinic and we can be bitten by snakes." "I have to suture a woman's perineum by candlelight." "The candle can fall and place be set alight. Candles have many hazards."

Participants stated that it was difficult to perform any task without electricity and that health services came to a standstill without lights. The participants reported that maternity cases were attended to by candlelight and that could hamper the delivery of quality care. To cut and suture episiotomies by candlelight may lead to complications that could be harmful to patients. This is supported by Lipinge and Botes (2002:22) who say that rural communities lack essential physical and social structures including water, communication and electricity.

Inadequate accommodation was a general problem experienced by the participants who rendered 24-hour service to the community. The accommodation arrangements at rural primary health-care facilities were inadequate. Two nurses shared a four-roomed house. It was difficult for them to have members of their own family with them.

The millions of rand spent by the South African Department of Health to recruit nurses to rural areas were wasted if management of the facility did not have a family-friendly policy (Hegney et al., 2002:132). It was evident that participants believed that this kind of policy did not exist at the nurses' facilities, as their children or spouses were not allowed to visit them. Nurses were forced to live in staff accommodation of a poor standard due to the high cost of private rental. The issue of accommodation was challenging, and support was needed for nurses in this area. Some of the nurses expressed the problem of communication. One of them said:

"I fear when there is no telecommunication, what might happen if an emergency case can come, who would need urgent transportation to hospital."

Most primary health-care facilities in Letaba sub-district in the Mopani region used a two-way radio communication system as means of communication. According to the Department of Health (South Africa, 2001:14), there should always be a working means of communication, such as a radio or telephone, in order to manage a primary health-care facility effectively. According to Doherty and Price (1998:315), ambulances based at hospitals responded to calls from members of the community or transferred the call to other hospitals some distance away.

In an evaluation of rural ambulances, Doherty and Price (1998:315) found that radiophones were the principal means of communication between clinics and ambulances. Van der Merwe (1999:1274) states that the telecommunication systems in rural areas are poor. Chalmers et al. (1998:113) state that nurses are expected to identify needs and determine how to meet them. Nurses should create a climate of healing for their clients. It is therefore important that their telecommunication system be improved for better and effective communication when rendering care.

\section{Category 3: Constraints in caring}

The following themes emerged from the category, 'constraints in caring': shortage of staff, long working hours, poor maintenance of aseptic techniques and inadequate supply of drugs. The participants named staff shortage as a barrier to the provision of adequate health care to their clients, as it exhausted them. One participant made the following remarks:

"We are terribly understaffed, we work very hard, and most of the time one is totally exhausted. When one nurse is on maternity leave or sick leave, there is no replacement, we have to cover her part of the work. This is tough."

Participants perceived the shortage of staff as their greatest challenge, a challenge that required them to use all their knowledge and various skills. At rural primary health-care facilities, professional nurses managed large numbers of patients every day. They had to assess, plan, implement and evaluate treatments, as well as conduct home visits. Due to the shortage of staff nurses, they sacrificed and worked long hours, which contributed to fatigue, stress and burnout. A lack of adequate staffing and organisational resources appeared to be the most characteristic of nurses practising in rural areas (Muus, Stratton, Dunkin \& Juhl, 1993:39).

Akisola and Ncube (2000:52) add that patients expect the best treatment, no matter what the staffing situation is. In some primary health-care facilities the number of professional nurses employed remained the same despite the increase in the use of their services. In a study of the effect of free health services on primary health-care nurses in the Vhembe district of Limpopo Province, Nemathaga (2002:39) found that the introduction of free health services was a factor that contributed to the shortage of nursing staff.

Shortage of staff and infrastructure problems such as water, affected the provision of quality health care. One of the participants said:

"We stay three to four days without water in the clinic, yet we are supposed to wash hands between patient examinations."

The inability to maintain aseptic techniques demoralised professional nurses working in rural primary healthcare settings. They feared that they might end up being ill due to poor hygienic practices and walking long distances to fetch water when they were off duty.

Participants mentioned inadequate supplies of drugs as a constraint to caring for clients. According to these participants, the supply of drugs did not cover the number of clients at the facility. The supply was exhausted before the next order was due. According to Thornton (1996:495), the Rural Health Clinic Service Act was passed in 1978 in order to improve primary health care for those who were medically underserved. Participants found that patients feared the consequences of the delayed delivery of chronic medication and felt that clients suffered when the drugs were not available. Participants mentioned that chronic patients feared that if medication from the hospital was not delivered in time they may experience problems. Participants mentioned that they had discovered that chronic patients lent medication to each other, and if one ran out of medication they even reduced the strength of their dose so that they would not run out of medication.

\section{Category 4: Relationship}

The theme that emerged from this category was the participants' separation from their families. Participants who rendered 24-hour services to the community were concerned that they could not be with their children. Participants felt that their children needed 
their mothers' guidance, as well as assistance with school work and other reassurance. Without their mothers' presence, children's progress at school often declined. In a study of the job satisfaction of nurses in rural Australia, Hegney and McCarthy (2000:348) found that nurses worked in rural areas primarily for family and social reasons.

According to Hegney et al. (2002:132), rural nurses would choose to remain in rural areas, if managerial structures recognised that they had roles and responsibilities, such as child care and housework, apart from their waged work. Flexible scheduling not only meets patients' needs, but also attracts nurses who cannot work traditional nursing shifts (Fuszard, Green, Kyjala \& Talley, 1994a:26). Separation from families for long periods of time could negatively affect nurses' marriages and their relationships with their children. The kinds of feelings expressed by the participants were often suppressed as a result of the culture of the work environment. Professional nurses had to be responsible and display an accurate image of the profession and the life of the patient had to be their first consideration (Gattuse \& Bevan, 2000:893)

\section{Category 5: Personal issues}

The following sub-categories emerged from the category 'personal issues':

Participants' negative experiences and participants' positive experiences.

In a study of rural nurses, Fuszard et al. (1994:42) found that salary compression is an acute problem in rural settings. The participants appreciated the salary they received, but said that part of the salary was usually spent on work-related items, such as phone calls to ambulances.

One participant attributed her lack of a full uniform to wear every day while on duty to an inadequate uniform allowance. Participants reported having to buy their own uniforms with their salaries. Stratton, Dunkin, Juhl, Ludtke and Gellar (1991:30) support this statement by indicating that working in rural areas makes it difficult for nurses' spouses to supplement their families' income.

Participants felt that providing 24-hour services for seven days in succession was tiring and as a result of calls during the night, they were not getting enough sleep. Unresolved issues that affected nurses were patient load, job stress, length of shifts, professional salaries versus hourly wages, provision of health care, career mobility and professional autonomy (Purnell et al., 2001:179).

Participants were very positive when speaking of being provided with inservice training on aspects such as tuberculosis (TB) and victim empowerment. According to Fuszard $e t$ al. (1994:21), rural administrators must develop their staff, so that they will have the employees they need to fulfil their mission. The effectiveness of such a strategy is supported by Busby and Busby $(2001: 308)$, who state that a continuity education programme is needed to prepare nurses to teach the community about safety issues, health promotion, illness, and prevention and management of chronic health problems in order to reduce their need for emergency services. Fuszard et al. (1994:36) state that professional growth is the responsibility of institutions as well as professionals, regardless of the setting.

Participants were satisfied with the delivery of medication for minor ailments and said they never ran out of stock, despite the large number of clients visiting the facility daily. According to Fuszard et al. (1994:38), some facilities have a pharmacy that supports them and is available virtually 24 hours a day. Hegney et al. (2002:131) add that a cohesive and effective team is facilitated by good communication.

\section{Recommendations}

\section{Incentives}

The promotion of professional practice incentives and clinical ladders are strategies that should be researched, disseminated and implemented in primary health-care facilities. A possibility is to create agency nurses for facilities from their own nursing staff. These nurses would do any extra work at the agency rate, thereby limiting unnecessary leave and lowering absenteeism rates. This would also ensure a higher standard of client care and build the morale of the staff, as they would be paid for the extra work rather than being refunded for it with extra days off.

\section{Scheduling of work hours}

Management should develop an overtime policy for their health-care facilities. This would supplement the professional nurses' salaries and assist with filling the gap in available human resources. The option of flexible scheduling should be created in order to meet the needs of the clients and attract professional nurses who cannot work traditional nursing shifts. Night duty should be introduced in place of a call system.

\section{Infrastructure}

\section{- Water supply}

Ground water should be accessed by means of boreholes at every primary health-care facility to supply water for use at the clinic and nurses' home. A standby tank of water should be kept full at all times.

\section{- Accommodation}

More houses should be built in order to accommodate professional nurses with families. A more family-friendly facility would meet the needs of professional nurses and the facility would be more likely to retain their services.

\section{- Communication}

Telephones should be installed at all facilities and a cell phone should be supplied by management with a limited number of units per month to be kept on hand for the use of nurses in cases of emergency.

\section{- $\quad$ Electricity}

A solar system should be installed at all facilities to supplement the electricity supply during power cuts.

\section{Conclusions}

This study revealed that nurses working in the primary health-care facilities in the rural areas of Greater Letaba sub-district in the Mopani district were experiencing emotional and physical strain as a result of a shortage of human and material resources, work overload, long working hours and infrastructural constraints. The areas with which they were dissatisfied outnumbered those they found satisfactory. They expressed concern about the lack of infrastructure and felt that their problems did not receive consideration when raised with the management of the facilities.

The conditions under which these professional nurses were working exposed them to emotional and physical strain and resulted in the facilities' 
difficulty in recruiting graduates and other professional nurses interested in the rural lifestyle. A lack of human resources was a national problem, and only worsened when it came to rural areas. Retaining professional nurses was also a problem, with many leaving to seek greener pastures. When clients complained about the poor conduct of some nurses, they used the excuse of being overworked and therefore feeling burnt out (Akisola \& Ncube, 2000:53). Batho Pele principles were developed to meet the needs of clients and encourage professionals to work hand-in-hand with their clients. However, nurses felt that clients abused those principles. Patients' rights were formulated to highlight the issues of informed choice regarding treatment of clients, but the overemphasis of those rights caused poor interpersonal relationships between clients and health professionals. Professional nurses were strained by the simultaneous demands of clients and the problems of a shortage of personnel.

Role overload caused a high rate of burnout. A great deal needed to be done if primary health-care services were to become acceptable, accessible and available to the community. The problem of human and material resource shortages needed to be dealt with. The emotional and physical strain nurses experienced in rural primary health-care facilities created obstacles to the provision of highquality care and caused tension in the relationships between nurses and clients. Clients' rights had to be respected, but some of these rights were a burden to the nurses. Professional nurses also had rights which had to be respected by the clients and the community. The smooth running of health-care services was dependent on the application of Batho Pele principles by health professionals, clients and the community.

A major challenge for the government is to develop specific policies regarding health programmes and services that meet the emerging health-care needs of rural communities. Administrators in primary health-care settings in rural areas should bring the needs of their facilities to the attention of those who influence healthcare policy. Strategies to retain professional nurses in primary healthcare settings must be formulated.

\section{List of references}

AKISOLA, HY \& NCUBE, E 2000: Rural health care provision in Botswana: The context of nursing, a practice and the expanded role of the nurse. Africa Journal of Nursing and Midwifery. 1:49-55.

AVERULL,JB 2002: Voices from the Gila: Health care issues for rural elders in south-western Mexico. Journal of Advanced Nursing. 40(6):654-62.

BRINK, HI 1996: Fundamentals of research methodology for health professionals. Cape Town: Juta.

BUSBY, A \& BUSBY, A 2001: Critical access hospitals: Rural nursing issues. jona, 31(6):301-10.

BUSBY, A \& RAUH, JR 1991: Implementing an ethics committee in rural institutions. Jona, 21(12): 18-25.

CHALMERS, KI; BRAMADAT, IJ \& ANDRUSYSZYN, MA 1998: The changing environment of community health practice and education: Perceptions of staff nurses, administrators and educators. Journal of Nursing Education. 37(3): 109-117.

DENNILL, K; KING, L; LOCK, M \& SWANEPOEL, T 1995: Aspects of primary health care. Halfway House: Thomson.

DE VOS, AS 1998: Research at grassroots level: A primer for the caring profession. Pretoria: Van Schaik.

DOHERTY, J \& PRICE, M 1998:

Evaluation of rural ambulance service. World Health Fonum. 19(3):315-8.

FUSZARD,B, GREEN, E; KUJALA,E \& TALLEY,B. 1994b: Rural magnet hospital of excellence (part 2). Jona. 24(2):35-41.

GATTUSO, S \& BEVAN, C 2000: Mother, patient, nurse: Women's emotion work in aged care. Journal of Advanced Nursing. 31(4): 892-99.

HEGNEY, D \& MCCARTHY, A 2000: Job satisfaction and nurses in rural Australia. Jona. 30(7/8):347-50.

HEGNEY,D; MCCARTHY,A; CLARK, CR \& GORMAN, D 2002: Retaining rural and remote area nurses: The Queensland, Australia experience. jona. 32(3): 128-35.

KLOPPER, H 1998: Nursing research.
Potchefstroom: Potchefstroom University.

LINCOLN, SY \& GUBA, EG 1985: Naturalistic inquiry. New Delhi: Sage.

LIPINGE, SN \& BOTES, AC.2002: Expectations of stakeholders regarding home care provision in rural Namibia. Curationis.: 25 (4).:21-31.

MOSZCZYNSKI, AB; HANEY, CJ \& VANCOUVER, BC 2002: Stress and coping of Canadian rural nurses caring for trauma patients who are transferred out. Journal of Emergencv Nursing. 28(6): 496-504.

MUUS, KJ; STRATTON, TJ; IUNKIN, JW \& JUHL, N 1993: Retaining registered nurses in rural community hospitals. jona. 23(3):38-43.

NEMATHAGA, LH 2002: Experiences of primary health care nurses on free health services in Vhembe region of the Limpopo Province Thohoyandou: UNIVEN. (MCur dissertation).

POLIT, DF \& BECK, CT 2004: Nursing research: Principles and methods Philadelphia: Lippincott, Williams \& Wilkins.

POLIT, DF \& HUNGLER, BP 1991: Nursing research: Principles and methods . Philadelphia: Lippincott.

PURNELL, MJ; HORNER, D; GONZALEZ, J \& WESTMAN, N 2001: The Nursing shortage: Revisioning the future. iona.31(4): 179-186.

DEPARTMENT OF HEALTH. 2001: Primary health care package. Pretoria: Government Printers.

STRATTON, TD; DUNKIN,JW; JUHL, N; LUDTKE, RI \& GELLER, JM 1991: Recruiting and retaining registered nurses in rural community hospitals. jona, 21(11):30-4.

THORNTON, CL 1996: Nurse practitioner in a rural setting. Advanced Practice Nursing. 31(3):495-505.

VAN DER MERWE,AS 1999: The power of women as nurses in South Africa. Journal of Advanced Nursing. 30(6): 12729.

WIENS, AG 1990: Expanded nurse 
autonomy: Model for small rural hospital. jona, 20(12): 15-22 